\title{
The activity of azithromycin against Leishmania (Viannia) braziliensis and Leishmania (Leishmania) amazonensis in the golden hamster model
}

\author{
A atividade da azitromicina contra a Leishmania (Viannia) braziliensis e a \\ Leishmania (Leishmania) amazonensis no modelo golden hamster
}

\author{
Ángel Sinagra ${ }^{1}$, Concepción Luna ${ }^{1}$, David Abraham ${ }^{2}$, Maria del Carmen Iannella ${ }^{3}$, \\ Adelina Riarte ${ }^{1}$ and Alejandro J. Krolewiecki ${ }^{4,5}$
}

\begin{abstract}
New therapeutic alternatives against leishmaniasis remain a priority. The activity of azithromycin against Leishmania (Leishmania) major has been previously demonstrated. Different responses among species of Leishmania make species-specific drug screening necessary. The activity of azithromycin against Leishmania (Viannia) braziliensis and Leishmania (Leishmania) amazonensis was evaluated in golden hamsters infected through footpad injections of metacyclic promastigotes, and compared with untreated controls and animals treated with meglumine antimoniate. Footpad thickness, lesion cultures and dissemination sites were analyzed. Treatment of golden hamsters with oral azithromycin at $450 \mathrm{mg} / \mathrm{kg}$ had no activity against infections with Leishmania (Leishmania) amazonensis. For infections due to Leishmania (Viannia) braziliensis, azithromycin demonstrated significant activity relative to untreated controls, but inferior to meglumine antimoniate, for controlling lesion size. Neither drug was able to totally eliminate parasites from the lesions. It was concluded that azithromycin has activity against Leishmania (Viannia) braziliensis but not against Leishmania (Leishmania) amazonensis in this model.
\end{abstract}

Key-words: Leishmania Viannia braziliensis. Leishmania Leishmania amazonensis. Azithromycin. Hamster.

\section{RESUMO}

Novas alternativas terapêuticas contra a leishmaniose são ainda uma prioridade. A atividade da azitromicina contra a Leishmania (Leishmania) major foi anteriormente demonstrada. Diferentes respostas entre as espécies de Leishmania fazem com que um screening de drogas especificas para espécies seja necessário. A atividade da azitromicina contra a Leishmania (Viannia) braziliensis e a Leishmania (Leishmania) amazonensis foi avaliada em Golden hamsters infectados a través de injeções de promastigotas metacíclicas e comparando com controles sem tratamento e animais tratados com antimoniato de N-metil-glucamina. Foram analisadas a espessura da pata, a cultura das lesões e disseminação para órgãos internos. A azitromicina oral em dose de $450 \mathrm{mg} / \mathrm{kg}$ não teve atividade contra a infecção por Leishmania (Leishmania) amazonensis. Para infecções devidas à Leishmania (Viannia) braziliensis, a azitromicina teve uma atividade significativa em relação aos controles sem tratamento, mas foi inferior ao antimoniato de N-metil-glucamina quanto ao controle do tamanho das lesões. Nenhuma das drogas conseguiu eliminar totalmente os parasitos das lesões. Foi concluído que a azitromicina tem atividade contra Leishmania (Viannia) braziliensis, mas não tem atividade contra Leishmania (Leishmania) amazonensis neste modelo.

Palavras-chaves: Leishmania Viannia braziliensis. Leishmania Leishmania amazonensis. Azitromicina. Hamster.

The search for new therapies against leishmaniasis in its different forms continues to be a clinical priority. Leishmania (Viannia) braziliensis has been identified as the causative agent of most cases of cutaneous and mucosal leishmaniasis in Argentina, although a role for Leishmania (Leishmania) amazonensis and Leishmania (Viannia) guyanensis has recently been described in a minority of cases $^{3}{ }^{8}$. Infection of golden hamsters with Leishmania (Viannia) braziliensis results in local lesions and dissemination ${ }^{13}$. In the case of infections with Leishmania (Leishmania) amazonensis, golden hamsters develop florid lesions at the inoculation site that tend to grow chronically with dissemination to metastatic foci. Treatments with

1. Instituto Nacional de Parasitología Dr. Mario Fatala Chabén, Buenos Aires, Argentina. 2. Department of Microbiology and Immunology, Thomas Jefferson University, Philadelphia, USA, 3. Mathematics Department, Facultad de Ciencias Económicas, Universidad de Buenos Aires, Buenos Aires, Argentina. 4. Fundación Huésped. Área de Investigaciones Clínicas. Buenos Aires, Argentina. 5. Instituto de Investigaciones en Enfermedades Tropicales Universidad Nacional de Salta. Sede regional Orán. SRN. Orán, Argentina.

Address to: Dr. Alejandro J. Krolewiecki. Pje. Angel Peluffo 3932. Buenos Aires (C1202ABB), Argentina.

Tel: 54 11-4981-1855. Fax: 5411 4982-4024

e-mail: alekrol@huesped.org.ar

Recebido para publicação em: 23/04/2007

Aceito em: 11/10/2007 
meglumine antimoniate are able to control but not to sterilize the lesions caused by both Leishmania (Viannia) braziliensis and Leishmania (Leishmania) amazonensis ${ }^{211}$.

The activity of azithromycin against Leishmania (Leishmania) major in vitro and in $\mathrm{BALB} / \mathrm{cByJ}$ mice has been previously demonstrated. In vitro, azithromycin significantly reduced parasite numbers in cell-free cultures, the number of amastigotes per macrophage and the number of infected macrophages. Treatment of BALB/cByJ mice with azithromycin caused diminished lesion size and parasite load ${ }^{6}$.

Azithromycin has a benign toxicity profile, good tolerance in pediatric populations, oral and parenteral formulations and a lack of contraindications during pregnancy (FDA category B $)^{14}$. This drug also has preferential active concentration in macrophages 5 .

The objective of this study was to determine the effect of azithromycin on Leishmania (Viannia) braziliensis and Leishmania (Leishmania) amazonensis infections of golden hamsters using experimental systems designed for each species.

\section{MATERIAL AND METHODS}

Drugs. Azithromycin (Zitromax ${ }^{\mathrm{TM}}$, Pfizer) powder was mixed in water to a dilution of $40 \mathrm{mg} / \mathrm{ml}$. Meglumine antimoniate (Lazar, Argentina) was used from vials containing $5 \mathrm{ml}$ of solution (1.5g of antimony, corresponding to $425 \mathrm{mg}$ of $\mathrm{SbV}$ ).

Parasites. The strains IFLA/BR67/PH8 of Leishmania (Leishmania) amazonensis and MHOM/AR/90LEA4 of Leishmania (Viannia) braziliensis were used. For both strains, promastigotes in the stationary phase were obtained from six-dayold in-vitro cultures in Senekjie medium with RPMI1640 (GIBCO, USA) and $20 \%$ fetal bovine serum at $26^{\circ} \mathrm{C}$. The parasites in these cultures originated from lesions in golden hamsters. Promastigotes for inoculation were counted in Neubauer chambers.

Animals. Male and female 55 to 65-day-old golden hamsters (Mesocriscetus auratus) bred at the animal facilities of the Mario Fatala Chabén National Parasitology Institute were used in the experiments. Throughout the experiments, the animals were housed in cages of two to three animals with food and water ad libitum. In every experiment, each group included at least five animals.

Infection and treatment. Animals were subcutaneously inoculated in the right footpad with $1 \times 10^{6}$ metacyclic promastigotes of Leishmania (Leishmania) amazonensis or $5 \times 10^{5}$ metacyclic promastigotes of Leishmania (Viannia) braziliensis using a 25g 5/8" needle. Drug treatments were started immediately after infections, at doses of $450 \mathrm{mg} / \mathrm{kg} /$ day for five days a week through an oral cannula for azithromycin and at doses of $60 \mathrm{mg} / \mathrm{kg} /$ day intramuscularly for five days a week for meglumine antimoniate, based on previous efficacy reports for hamsters infected with Leishmania (Viannia) panamensis ${ }^{15}$. The dose of azithromycin was chosen based on the maximum dose that was well tolerated by the animals in a preliminary experiment. The treatment duration was four weeks for meglumine antimoniate; treatments with azithromycin lasted eight weeks for Leishmania (Leishmania) amazonensis and five weeks for Leishmania (Viannia) braziliensis. The differential duration of the treatments with azithromycin was defined in the experimental design based on the known duration and aggressiveness of lesions due to Leishmania (Leishmania) amazonensis compared with Leishmania (Viannia) braziliensis ${ }^{13}$.

Lesion size was determined weekly by measuring the thickness of the infected and contralateral footpad using a digital caliper (Schwyz Model SC111101E, Switzerland), and the difference between the footpads was calculated. Leishmania (Leishmania) amazonensis infections were followed for up to 15 weeks and Leishmania (Viannia) braziliensis infections for up to 7 weeks.

Dissemination was studied by taking samples from homolateral popliteal lymph nodes, liver and/or spleen. These tissues were processed and cultured in Senekjie medium for 30 days, after which the presence of live parasites was determined. Semiquantitative parasite counts were made on biopsy tissue of approximately $10 \mathrm{mg}$ that was taken from the lesion at the end of the experiment. This tissue was weighed and a homogenate was prepared in a grinder with RPMI1640 containing 20\% fetal calf serum. Serial tenfold dilutions were prepared in 96-well plates and incubated at $26^{\circ} \mathrm{C}$ for 14 days. The highest dilution with moving parasites was the final titer for each sample. Each biopsy was cultured in duplicate.

Data analysis. All experiments were performed at least in duplicate; the data presented represent a summary from all experiments. The data were analyzed for statistical significance with the Mann-Whitney test or Student $t$ test when appropriate. Differences were considered significant with $P$ values of $<0.05$. The data analysis was performed using SPSS for Windows, version 12.0 (SPSS Inc, USA).

\section{RESULTS}

Effect of azithromycin on Leishmania (Leishmania) amazonensis infections. Footpad lesions developed in untreated infected golden hamsters within one week of infection. Treatment of infected animals with azithromycin had no effect on the size of the lesions (Figure 1). Semiquantitative analysis of parasite load in the lesion and cultures of regional lymph nodes at 10 weeks also showed no effect compared with untreated animals (Table 1). Meglumine antimoniate was effective for controlling the development of lesions for 10 weeks, after which the lesions increased in size until the end of the experiment (Figure 1). In a significant number of animals treated with meglumine antimoniate, at 10 weeks postinfection, parasites were not recovered from the lesions and dissemination was blocked (Table 1). However, at 15 weeks postinfection there was uniform positivity of lesion and popliteal lymph node cultures in all groups. Dissemination to the liver was observed in one of the six animals in the untreated control group and in none of the treated animals (five with meglumine antimoniate and five with azithromycin) at 10 weeks postinfection, 


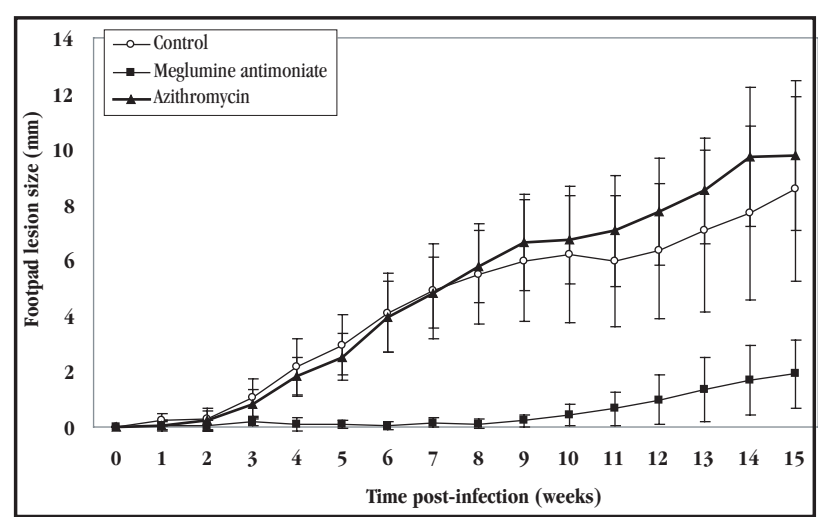

$\mathrm{P}<0.05$ between meglumine antimoniate and the other groups from week 4 until the end of the experiment.

Figure 1 - Effect of treatment with $450 \mathrm{mg} / \mathrm{kg}$ of oral azithromycin for 8 weeks or $60 \mathrm{mg} / \mathrm{kg}$ of subcutaneous meglumine antimoniate on the development of footpad swelling caused by infections with $1 x 1^{6}$ metacyclic promastigotes of Leishmania (Leishmania) amazonensis in Golden hamsters. Ten animals per group were followed until week 10, when half were sacrificed and the rest were followed until week 15. The values represent the mean \pm standard deviation difference between the thickness of the infected and the contralateral footpad.

but this difference did not reach statistical significance. Similarly, dissemination to the spleen was observed in two of the ten untreated animals but in none of those treated with meglumine antimoniate (nine) or azithromycin (ten).

Table 1 - Positive cultures of lesions (skin), regional lymph nodes, liver and spleen at 10 weeks post infection in animals infected with Leishmania (Leishmania) amazonensis IFLA/BR67/PH8 and treated with meglumine antimoniate for 4 weeks or azithromycin for 8 weeks. Data represents number of positive animals/number of animals in the group.

\begin{tabular}{lrcc}
\hline & Control & Meglumine antimoniate & Azithromycin \\
\hline Lesion & $10 / 10$ & $5 / 10^{*}$ & $9 / 9$ \\
Lymph node & $8 / 10$ & $2 / 10^{* *}$ & $6 / 8$ \\
Liver & $1 / 6$ & $0 / 5$ & $0 / 5$ \\
Spleen & $2 / 10$ & $0 / 10$ & $0 / 9$ \\
\hline
\end{tabular}

${ }^{*} \mathrm{p}<0.01$ compared to other 2 groups.

$* * \mathrm{p}=0.01$ compared to control and 0.02 compared to azithromycin.

Effect of azithromycin on Leishmania (Viannia) braziliensis infections. Statistically significant increases in footpad thickness developed at one week postinfection in untreated animals and in animals treated with azithromycin. At three weeks postinfection, the animals treated with meglumine antimoniate developed lesions. Treatments with meglumine antimoniate resulted in lesions with delayed appearance and lower peak swelling (Figure 2 ). The animals treated with azithromycin had lesions that were significantly smaller than those in untreated controls and larger than those in golden hamsters treated with meglumine antimoniate, from three weeks postinfection $(\mathrm{p}=0.002)$ until the end of the experiment (Figure 2). Recovery of viable parasites from the lesions at seven weeks postinfection was performed without evidence of significant differences between groups. At seven weeks, dissemination was confirmed in popliteal lymph nodes homolateral to the lesions in all groups, without evidence of significant differences between them (Table 2). Dissemination of parasites to the liver was detected in one out of 18 animals, in the meglumine antimoniate group, at seven weeks postinfection (Table 2).

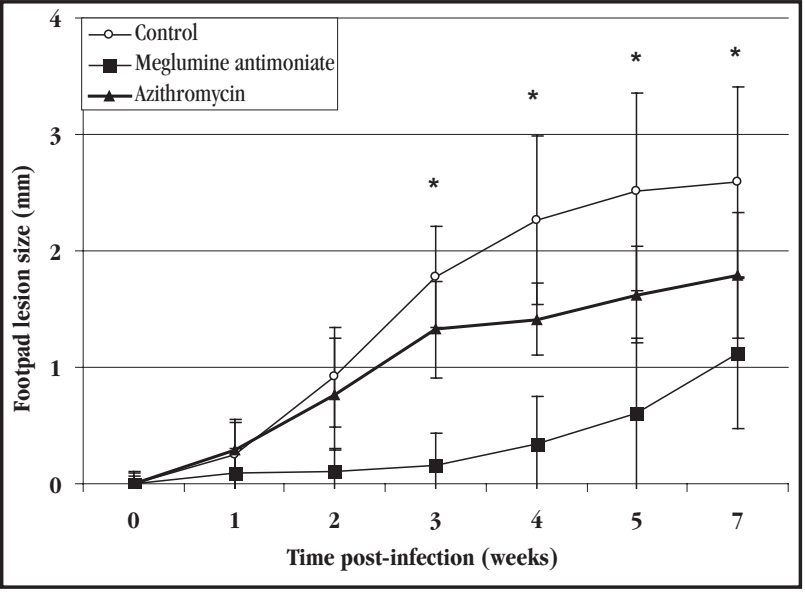

$* \mathrm{p}<0.05$ for comparisons between all three groups.

Figure 2 - Effect of treatment with $450 \mathrm{mg} / \mathrm{kg}$ of oral azithromycin for 5 weeks or $60 \mathrm{mg} / \mathrm{kg}$ of subcutaneous meglumine antimoniate for 4 weeks on the development of footpad swelling caused by infections with $5 \times 10^{5}$ metacyclic promastigotes of Leishmania (Viannia) braziliensis in Golden hamsters. Ten animals per group were followed throughout each of the 2 repetitions of the experiment. The values represent the mean \pm standard deviation difference between the thickness of the infected and the contralateral footpad.

Table 2 - Positive cultures of lesions (skin) regional lymph nodes and liver at 7 weeks post infection in animals infected with Leishmania (Viannia) braziliensis MHOM/AR/90LEA4 and treated with meglumine antimoniate for 4 weeks or azithromycin for 5 weeks. No significant differences between groups were identified. Data represents number of positive animals/number of animals in the group.

\begin{tabular}{lccc}
\hline & Control & Meglumine antimoniate & Azithromycin \\
\hline Lesion & $16 / 16$ & $14 / 18$ & $13 / 14$ \\
Lymph node & $12 / 16$ & $10 / 18$ & $11 / 14$ \\
\hline Liver & $0 / 16$ & $1 / 18$ & $0 / 14$ \\
\hline
\end{tabular}

\section{DISCUSSION}

Our results show that Leishmania (Leishmania) amazonensis infections in golden hamsters are resistant to azithromycin, such that the treated animals developed infections indistinguishable from untreated controls. Meglumine antimoniate was used as a positive control and demonstrated its efficacy in limiting infections. Control over the parasite was however not absolute, in that lesions and local lymph nodes were infected with parasites 15 weeks postinfection (11 weeks after treatment completion). This finding is consistent with previous reports regarding treatment of Leishmania (Leishmania) amazonensis and other species of Leishmania with antimony compounds, in hamsters ${ }^{2}$.

The lesion size in the animals infected with Leishmania (Viannia) braziliensis was significantly reduced by treatment with azithromycin and meglumine antimoniate. Azithromycin was unable to totally block the development of foot pad swelling, although the lesions were significantly smaller in treated animals than in untreated controls. These results mirror those seen in BALB/cByJ mice infected with Leishmania (Leishmania) major and treated with azithromycin ${ }^{6}$, in which animals were treated subcutaneously using regimens of 100 to $200 \mathrm{mg} / \mathrm{kg} /$ day for 
eight weeks. Meglumine antimoniate was significantly superior to oral azithromycin for controlling infection by Leishmania (Viannia) braziliensis. However, as in the case of Leishmania (Leishmania) amazonensis, lesions developed in the mice treated with meglumine antimoniate at the end of the experimental period. This observation confirms previous reports that meglumine antimoniate does not eliminate all Leishmania parasites from golden hamsters using similar treatment regimens ${ }^{15}$.

The use of positive and negative controls gives support to the conclusions and makes it unlikely that the differences in the results between the two species described in this report might be related to the different inoculum used for each species (1x $10^{6}$ for Leishmania (Leishmania) amazonensis and $5 \times 10^{5}$ for Leishmania (Viannia) braziliensis). The effects of azithromycin and meglumine antimoniate at higher and lower inoculum doses or in different therapeutic schedules were not investigated.

The mechanism of action of azithromycin against Leishmania is unknown. Azithromycin has been shown to have immunomodulatory effects in humans with bronchiolitis obliterans ${ }^{4}$, and treatment of macrophages with azithromycin enhanced the elimination of fungal pathogens ${ }^{16}$. Alternatively, it is possible that azithromycin has direct antimicrobial activity on the parasites. In the case of pentavalent antimonials, with over 50 years of use for treating leishmaniasis, their mechanism of action is also still uncertain: both direct and immune-mediated mechanisms have been implicated 9 .

In addition to the preclinical studies performed on mice for evaluating azithromycin against Leishmania parasites $^{6}$, the clinical experiences include an uncontrolled study that involved 20 patients with cutaneous leishmaniasis in an area endemic for Leishmania (Viannia) braziliensis treated with variable doses of azithromycin for two to ten days with a cure rate of $85 \%{ }^{10}$. Contrasting with these findings, in an area endemic for Leishmania (Leishmania) major in Syria, no cures were recorded among 45 patients with cutaneous leishmaniasis using ten-day cycles of azithromycin ${ }^{1}$. Three cases of mucosal leishmaniasis with contraindications for the use of antimonials were successfully treated with three cycles of ten days of azithromycin in Brazil ${ }^{12}$.

Based on the discrepant responses of these species to azithromycin, clinical trials aimed at testing the findings from the current study must take into consideration the species involved in the treated patients. In conclusion, azithromycin has activity against Leishmania (Viannia) braziliensis but not against Leishmania (Leishmania) amazonensis in golden hamsters. This activity is inferior to meglumine antimoniate for lesion control, and yet both drugs failed to eliminate all parasites from the lesions. Further studies should evaluate the clinical use of azithromycin as an oral option for treating American cutaneous leishmaniasis caused by Leishmania (Viannia) braziliensis.

\section{ACKNOWLEDGEMENTS}

Sergio Sosa Estani for his contribution and comments and Leandro Cahn, Pablo López and Omar Mussmano for assistance with the illustrations. This study was supported by an educational grant from Pfizer.

\section{REFERENCES}

1. Daoud S, Boushi L. Azithromycin, ineffective in the treatment of old-world cutaneous leishmaniasis. International Journal of Dermatology 45: 1126-1128, 2006.

2. Figueiredo EM, Silva JC, Brazil RP. Experimental treatment with sodium stibogluconate of hamsters infected with Leishmania (Leishmania) chagasi and Leishmania (Leishmania) amazonensis. Revista da Sociedade Brasileira de Medicina Tropical 32: 191-193, 1999.

3. Frank FM, Fernandez MM, Taranto NJ, Cajal SP, Margni RA, Castro E, Thomaz Soccol V, Malchiodi EL. Characterization of human infection by Leishmania spp. in the Northwest of Argentina: immune response, double infection with Trypanosoma cruzi and species of Leishmania involved. Parasitology 126: 31-39, 2003.

4. Gerhardt SG, McDyer JF, Girgis RE, Conte JV, Yang SC, Orens JB. Maintenance azithromycin therapy for bronchiolitis obliterans syndrome: results of a pilot study. American Journal of Respiratory and Critical Care Medicine 168: 121-125, 2003.

5. Gladue RP, Bright GM, Isaacson RE, Newborg MF. In vitro and in vivo uptake of azithromycin (CP-62,993) by phagocytic cells: possible mechanism of delivery and release at sites of infection. Antimicrobial Agents and Chemotherapy 33: 277-282, 1989.

6. Krolewiecki A, Leon S, Scott P, Abraham D. Activity of azithromycin against Leishmamia major in vitro and in vivo. The American Journal of Tropical Medicine and Hygiene 67: 273-277, 2002

7. Krolewiecki A, Scott P, Abraham D. The anti-Leishmania activity of azithromycin in an in-vitro model. Revista da Sociedade Brasileira de Medicina Tropical 32: 137, 1999.

8. Marco JD, Barroso PA, Calvopiña M, Kumazawa H, Furuya M, Korenaga M, Cajal SP, Mora MC, Rea MMJ, Borda CE, Basombrío MA, Taranto NJ, Hashiguchi Y. Species assignation of Leishmania from human and canine American tegumentary leishmaniasis cases by multilocus enzyme electrophoresis in North Argentina. The American Journal of Tropical Medicine and Hygiene 72: 606-611, 2005.

9. Ouellette M, Drummelsmith J, Papadopoulou B. Leishmaniasis: drugs in the clinic resistance and new developments. Drug Resistance Updates 7: 257-266, 2004.

10. Prata A, Silva-Vergara ML, Costa L, Rocha A, Krolewiecki A, Silva JC, Paula EV, Pimenta Junior FG, Giraldo LER. Efficacy of azithromycin in the treatment of cutaneous leishmaniasis. Revista da Sociedade Brasileira de Medicina Tropical 36: 65-69, 2003.

11. Schubach A, Marzochi MCA, Cuzzi-Maya T, Oliveira AV, Araújo ML, Oliveira ALC, Pacheco RS, Momen H, Conceicao-Silva F, Coutinho SG, Marzochi KBF. Cutaneous scars in American tegumentary leishmaniasis patients: a site of Leishmania (Viannia) braziliensis persistence and viability eleven years after antimonial therapy and clinical cure. The American Journal Tropical Medicine and Hygiene 58: 824-827, 1998

12. Silva-Vergara ML, Almeida-Silva L, Maneira FRZ, Silva AG, Prata A. Azithromycin in the treatment of mucosal leishmaniasis. Revista do Instituto de Medicina Tropical de Sao Paulo 46: 175-177, 2004.

13. Sinagra A, Riarte A, Luna C, Campanini A, Segura EL. Leishmania (Viannia) braziliensis: biological behavior in golden hamsters of isolates from Argentine patients. The American Journal of Tropical Medicine and Hygiene 57: 115-118, 1997.

14. Sivapalasingam S, Steigbigel N. Macrolides, clindamycin and ketolides, In: Mandell G, Bennett J, Dolin R (eds) Principles and Practice of Infectious Diseases, Elsevier Churchill Livingstone: Philadelphia, PA 396-417, 2005.

15. Travi BL, Martinez JE, Zea A. Antimonial treatment of hamsters infected with Leishmania (Viannia) panamensis: assessment of parasitological cure with different therapeutic schedules. Transactions of the Royal Society of Tropical Medicine and Hygiene 87: 567-569, 1993.

16. Xu G, Fujita J, Negayama K, Yuube K, Hojo S, Yamaji Y, Kawanishi K, Takahara J. Effect of macrolide antibiotics on macrophage functions. Microbiology \& Immunology 40: 473-479, 1996. 